$r=$ activity coefficient, see Eq. (1)

$\gamma^{\prime}=y_{i} P / x_{i} P_{i}^{\circ}$

$\Lambda=$ binary parameter of Wilson equation

〈Subscript〉

$a z=$ refers to azeotropic point

$1=$ refers to methyl acetate

$2=$ refers to methanol

3 = refers to water

\section{Literature cited}

1) Balachov, M. I., A. V. Grishunin and L. A. Serafimov: Zh. Fiz. Khim., 41, 1555 (1966)

2) Barker, J. A.: Australian J. Chem., 6, 207 (1953)

3) Francis, A. W.: "Critical Solution Temperatures" Advances in Chem. Ser., No. 31, Am. Chem. Soc. (1961)
4) Hirata, M. and S. Suda,: Kakagu Kōgaku, 31, 759 (1967)

5) Hirata, M., S. Suda, T. Hakuta and K. Nagahama: J. Chem. Eng. Japan, 2, No. 2, 143 (1969)

6) Horseley, L. H.: "Azeotropic Data" Advances in Chem. Ser., No. 6, Am. Chem. Soc. (1952)

7) Nagahama, K. and M. Hirata: J. Chem. Eng. Japan, 3, No. 2, 146 (1970)

8) Nagahama, K., I. Suzuki and M. Hirata: To be published in J. Chem. Eng. Japan

9) Scatchard, G.: Chem. Rev., 44, 7 (1949)

10) Suda, S.: Doctoral thesis, Chem. Eng., Tokyo Metropolitan University, Tokyo (1967)

11) Tejima, T., S. Hiyoshi, H. Matsuda, S. Monma and S. Iwaba: J. Chem. Soc. Japan, 55, 47 (1952)

12) Wilson, G. M.: J. Am. Chem. Soc., 86, 127 (1964)

\title{
TERNARY LIQUID-LIQUID EQUILIBRIA FOR THE SYSTEMS SODIUM LIQUID AMMONIA SOLUTION AND BENZENE OR CYCLOHEXENE*
}

\author{
KATSUJI NODA, KATSUFUMI INOUE**, KURAJI SATO***, \\ KOSUKE TANAKA**** AND KIYOHARU ISHIDA \\ Department of Chemical Engineering, Shizuoka University, \\ Hamamatsu, Japan
}

\begin{abstract}
Ternory liquid-liquid equilibrium data for the systems benzene-sodium-ammonia and cyclohexene-sodium-ammonia were measured at $20^{\circ} \mathrm{C}$. A method for predichion of the mutual solubility of sparingly soluble mixtures in the ternary liquid-liquid equilibria was proposed by the application of Ishida's correlation using the data of the ternary liquidliquid equilibria. On the basis of the above results, a point at which solid and heterogeneous liquids are in equilibrium was determined.
\end{abstract}

The manufacture of 1,4-cyclohexadiene by the reduction of benzene in sodium-liquid ammonia solution has recently attracted increasing attention by virtue of many advantages ${ }^{1)}$. To separate the products from the reactions, it is necessary in this process to know the precise equilibrium data for the systems benzene-sodium-ammonia and cyclohexenesodium-ammonia.

The properties of alkali metal-ammonia solutions have been widely investigated from many view-points, but no study of the reduction of aromatic hydrocarbons in a sodium-liquid ammonia solution is found in the literature to the present authors' knowledge.

Although reaction of sodium with liquid ammonia yields sodium amide and hydrogen even in the absence of catalyst such as ferric oxide, the rate of reaction is so small that the influence on the variation

* Received on February 18, 1971

** Mitsubishi Heavy Ind. Ltd.

*** Niigata Tekkosho

**** Osaka Gas Co., Ltd. of the composition of this solution can be neglected ${ }^{6}$. However, since sodium-liquid ammonia solution reacts rapidly with 1,4-cyclohexadiene at room temperature, it was impossible to determine the phase relationships for the systems containing 1,4-cyclohexadiene.

The ternary liquid-liquid equilibria for the systems of sodium-liquid ammonia solution and benzene or cyclohexene at $20^{\circ} \mathrm{C}$ were determined neglecting the production of sodium amide.

\section{Materials and Methods}

Liquid ammonia used in this work was purified from the commercial product by repeating its careful distillation more than three times under pressure. Commercially available benzene was further purified by the usual method and the fraction of boiling point $80.0^{\circ} \sim 80.1^{\circ} \mathrm{C}(1 \mathrm{~atm})$, melting point $5.53^{\circ} \mathrm{C}(1 \mathrm{~atm})$, $d_{4}^{20} 0.8784, n_{D}^{20} 1.5011$ was used.

Sodium-liquid ammonia solution was prepared in a pressure glass bottle having a glass filter, as shown 


\begin{tabular}{|c|c|c|c|c|c|}
\hline $\begin{array}{l}\text { Table } \\
\text { tions a }\end{array}$ & $\begin{array}{l}\text { Benzene-s } \\
20^{\circ} \mathrm{C} \text { [wt. }\end{array}$ & $\begin{array}{l}\text { odium-c } \\
\%]\end{array}$ & onia & rium & \\
\hline Hydroc & rbon-rich & hase & Ammo & ia-rich $\mathrm{ph}$ & Lase \\
\hline $\begin{array}{l}\text { Ben- } \\
\text { zene }\end{array}$ & Sodium & $\begin{array}{l}\text { Am- } \\
\text { monia }\end{array}$ & $\begin{array}{l}\text { Ben- } \\
\text { zene }\end{array}$ & Sodium & $\begin{array}{l}\text { Am- } \\
\text { monia }\end{array}$ \\
\hline 87.3 & 0.02 & 12.7 & 2.1 & 14.1 & 83.9 \\
\hline 77.1 & 0.05 & 22.9 & 2.6 & 12.5 & 84.9 \\
\hline 69.0 & 0.1 & 30.9 & 3.5 & 11.0 & 85.5 \\
\hline 51.7 & 0.3 & 48.0 & 4.2 & 9.3 & 86.5 \\
\hline 47.5 & 0.4 & 52.1 & 5.3 & 8.6 & 86.1 \\
\hline 37.3 & 0.7 & 62.0 & 7.6 & 7.3 & 85.7 \\
\hline & lait point & & 13.6 & 4.2 & 82.2 \\
\hline $\begin{array}{l}\text { Table } 2 \\
\text { position }\end{array}$ & $\begin{array}{l}\text { Cyclohex } \\
\text { at } 20^{\circ} \mathrm{C}\end{array}$ & wt. $\%]$ & monia & equilibriu & com \\
\hline Hydroc & rbon-rich & hase & Ammo & ia-rich ph & lase \\
\hline $\begin{array}{l}\text { Cyclo- } \\
\text { hexene }\end{array}$ & Sodium & $\begin{array}{l}\text { Am- } \\
\text { monia }\end{array}$ & $\begin{array}{l}\text { Cyclo- } \\
\text { hexene }\end{array}$ & Sodium & $\begin{array}{l}\text { Am- } \\
\text { monia }\end{array}$ \\
\hline 90.61 & 0 & 9.39 & 17.81 & 0 & 82.19 \\
\hline 91.0 & 0.02 & 9.0 & 12.7 & 2.1 & 85.2 \\
\hline 91.8 & 0.02 & 8.2 & 8.3 & 2.9 & 88.8 \\
\hline 91.9 & 0.03 & 8.1 & 5.3 & 5.6 & 89.1 \\
\hline 92.4 & 0.04 & 7.8 & 3.9 & 8.9 & 87.2 \\
\hline 95.4 & 0.02 & 4.6 & 1.6 & 13.7 & 84.7 \\
\hline
\end{tabular}

in Fig. 1. After filtration of the almost insoluble sodium hydroxide, a part of this solution was transferred through the valve joint into a measuring bottle of about $50 \mathrm{cc}$ volume, already containing about 10 grams of hydrocarbon. Care was taking to evacuate and desiccate the measuring bottle and the connecting parts to avoid contamination of the system with air and water vapor.

Ternary liquid-liquid equilibria were determined by a method slightly modified from those reported in the previous paper $^{5}$. First, the composition of sodium-liquid ammonia solution was determined by chemical analysis, and secondary hydrocarbon was introduced and weighed. Liquid compositions were corrected slightly for the amount of components existing as vapor by measuring the volume of vapor space and total pressure, assuming that the concentrations of hydrocarbons could be neglected in the vapor phase.

An aliquot of homogeneous ammonia-rich phase in a measuring bottle, in equilibrium at $20^{\circ} \mathrm{C}$, was effused carefully and slowly into another evacuated pressure bottle (receiver) through a syringe needle. A trace of solution in the connecting part was washed into the receiver by liquid ammonia condensed at that part which distilled off from the receiver until the blue color disappeared. Then, ammonia was evaporated through the needle valve and absorbed in $2 \mathrm{~N}$ sulfuric acid solution. The concentration of ammonia was found by titrating the excess sulfuric acid of $2 \mathrm{~N}$ acid solution which absorbed all ammonia with $0.5 \mathrm{~N}$ sodium hydroxide solution using methylred as an indicator. Sodium metal in receiver was converted to sodium methylate and titrated with $0.1 \mathrm{~N}$ hydrochloric acid. Thus the composition of ammonia-rich phase was found. The composition of hydrocarbon-rich phase was determined in a similar way.

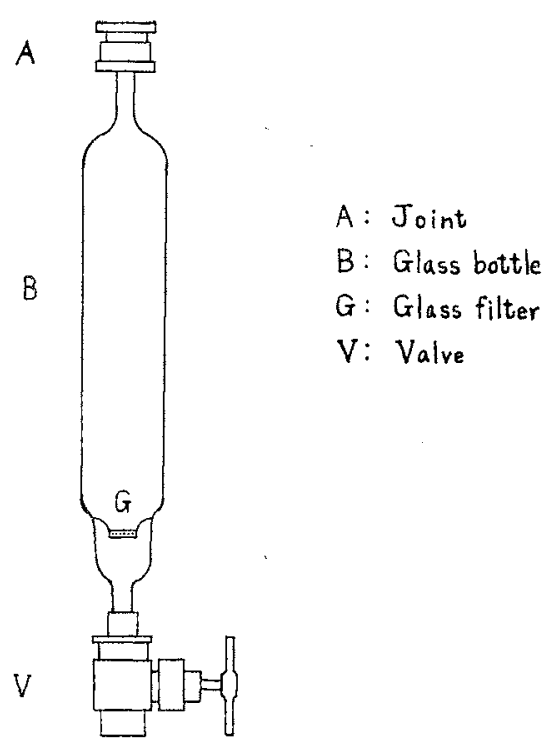

Fig. 1 Glass bottle having a glass filter

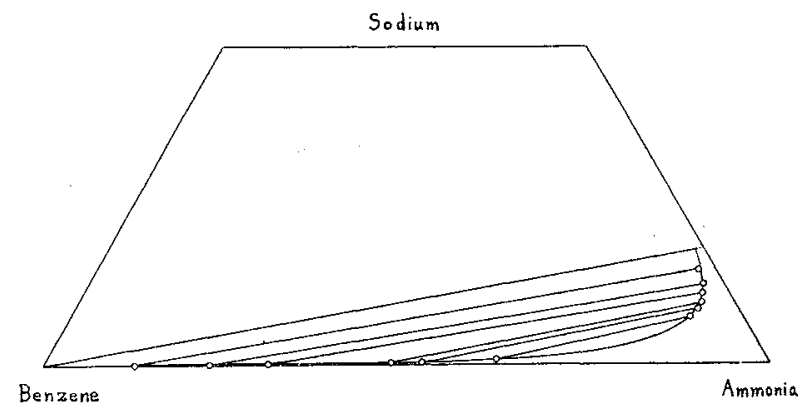

Fig. 2 Benzene-sodium-ammonia system at $20^{\circ} \mathrm{C}$, wt. fraction

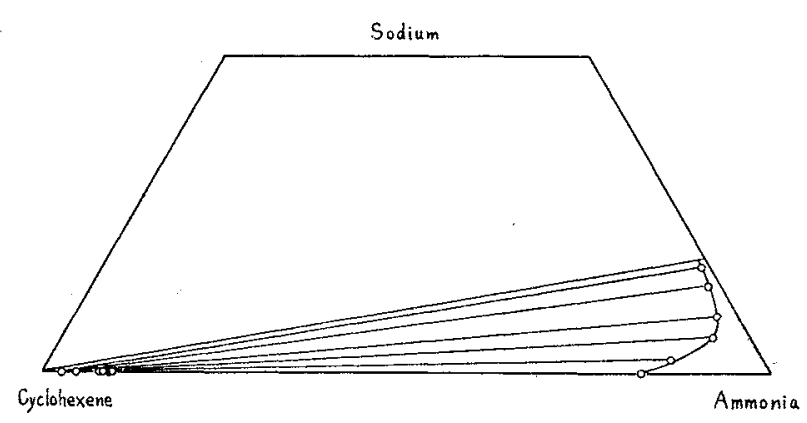

Fig. 3 Cyclohexen-sodium-ammonia system at $20^{\circ} \mathrm{C}$, wt. fraction

\section{Results and Discussion}

The experimental results for the systems benzenesodium-ammonia and cyclohexene-sodium-ammonia at $20^{\circ} \mathrm{C}$ are given in Tables 1 and 2, and are plotted in Figs. 2 and 3, respectively. The obtained tie lines pass through the points representing total mixtures, and material balance checks satisfactorily. Tie-line data for the former system in the range of liquid phase are fairly well correlated by Hand ${ }^{2)}$, 


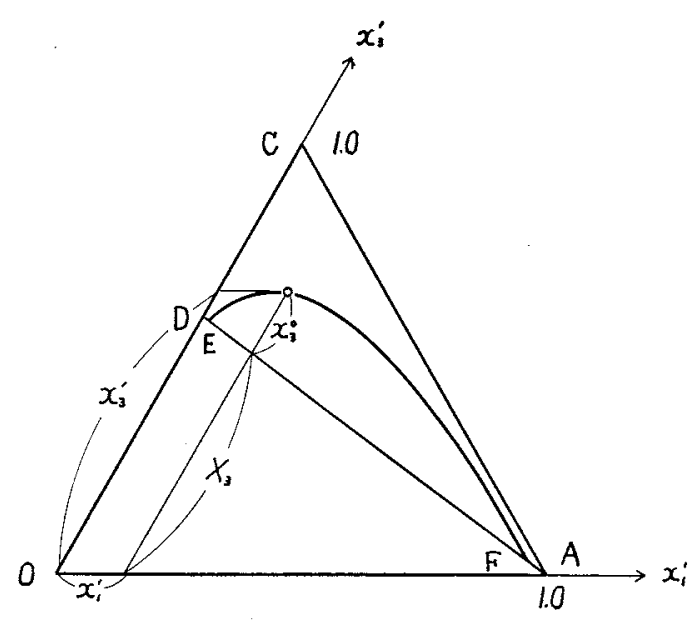

Fig. 4 Schematic diagram for transformation of the coordinates

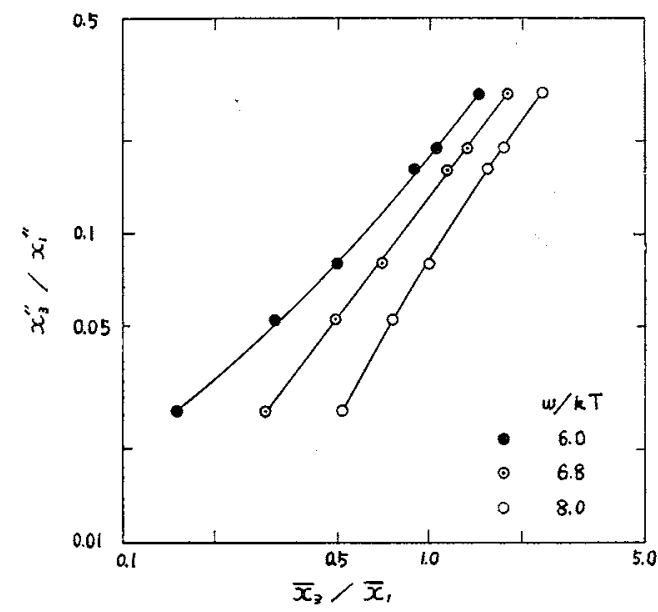

Fig 5 Variation of relationships between $x_{3}^{\prime \prime} / x_{1}^{\prime \prime}$ and $\overline{\boldsymbol{x}}_{3} / \overline{\boldsymbol{x}}_{1}$ depending on the values of $\mathrm{w} / \mathrm{k} T$

Othmer) and Ishida ${ }^{3)}$ coordinates. Plait point was estimated according to Treybal et al. ${ }^{8}$.

As will be clear from Figs. 2 and 3, it is observed that the increasing concentration of sodium in the mixtures decreases the solubilities of hydrocarbon in liquid ammonia, and solid phase appears. This is illustrated in Fig. 4. The solid phase will appear in the range of triangle ADO. In this paper we will discuss the range of liquid-liquid phase.

Since $\overline{\mathrm{OA}}$ and $\overline{\mathrm{OC}}$ are considered to be base lines in skew coordinates in Fig. 4, $\overline{\mathrm{AD}}$ is represented by

$$
X_{3}=p x_{1}^{\prime}+q
$$

where $x_{1}^{\prime}$ denotes the weight fraction of hydrocarbon and $p$ and $q$ are defined from solubility of sodium in liquid ammonia at a given temperature. For this system at $20^{\circ} \mathrm{C}, p$ and $q$ are -0.819 , and 0.819 , respectively9). The concentration of the third component (ammonia) more than $\overline{\mathrm{AD}}$ may be represented by

$$
x_{3}^{\circ}=x_{3}^{\prime}-X_{3}
$$

Table 3 Estimated values in the three condensed phase

region $[$ wt. $\%$ ]

Benzene-sodium-ammonia system

$\begin{array}{cccc} & \text { Benzene } & \text { Sodium } & \text { Ammonia } \\ \mathrm{E}^{*} & 1.0 & 17.9 & 81.1 \\ \mathrm{~F}^{*} & 99.99 & 0.002 & 0.009 \\ * & \text { These points are shown in Fig. } & \end{array}$

* These points are shown in Fig. 4.

Then, the new weight fraction is defined as follows

$$
\begin{aligned}
x_{1}=\frac{x_{1}^{\prime}}{x_{1}^{\prime}+x_{2}^{\prime}+x_{3}^{\circ}}, \quad x_{2} & =\frac{x_{2}^{\prime}}{x_{1}^{\prime}+x_{2}^{\prime}+x_{3}^{\prime}}, \\
x_{3} & =\frac{x_{3}^{\circ}}{x_{1}^{\prime}+x_{2}^{\prime}+x_{3}^{\circ}}
\end{aligned}
$$

Applying the above correlation, it is possible to transform the coordinates of the phase diagram into liquid phase region only. The treatment of these systems will be entirely the same as those of the previous paper4), where the method of correlating ternary liquid equilibrium data with the theory of regular solution has already been discussed. In the zeroth approximation, which is the simplest solution of the theory, the conjugated phase in cases of the symmetrical type with respect to component 1 and 2 are obtained from Eq. (4)

$$
-\frac{\bar{x}_{3}}{\bar{x}_{1}}=\frac{\left(\bar{x}_{2} / \bar{x}_{1}-1\right) w / k T}{\ln \left(\overline{x_{2}} / \overline{x_{1}}\right)}-\left(\frac{\bar{x}_{2}}{\bar{x}_{1}}+1\right)
$$

in which $\bar{x}$ is weight fraction of components and $w$ is interchange energy of a pair of nearest neighbors, one being of species 1 and the other species $2, k$ is the Boltzmann constant and $T$ is absolute temperature. The value of $w / k T$ may be obtained from the mutual solubility data of the nonconsolute component with

$$
\frac{w}{k T}=\left[\frac{\ln \bar{x}_{2}-\ln \bar{x}_{1}}{\bar{x}_{2}-\bar{x}_{1}}\right]_{0}
$$

where the subscript o refers to the binary solutions of the diluent 2, and the solvent 1 . However, the accurate evaluation of the parameter might be difficult from mutual solubility data in cases of sparingly soluble mixtures, or from data determined by impure reagents for the solvent or the diluent contaminated with the solute.

Rewriting Eq.(5)

$$
\frac{w}{k T}=\frac{1}{\frac{\bar{x}_{2}-\bar{x}_{1}}{\ln \bar{x}_{2}-\ln \bar{x}_{1}}}=\frac{1}{\bar{x}_{l m}}
$$

the parameter $w / k T$ may be estimated as the reciprocal of logarithmic mean of $\bar{x}_{1}$, and $\bar{x}_{2}$. In other words, since parameter $w / k T$ is assumed constant at a constant temperature in the theory, the solubility of diluent and solvent in symmetrical regular ternary mixtures can be estimated from the logarithmic mean of $\bar{x}_{1}$ and $\bar{x}_{2}$ with $\bar{x}_{1}+\bar{x}_{2}=1$. Accordingly, the value of $w / k T$ might be evaluated from the linear plots of $x_{3}^{\prime \prime} / x_{1}^{\prime \prime}$ against $\bar{x}_{3} / \bar{x}_{1}$ on log-log coordinates: smaller values of the parameter will give concave curves and greater values convex curves, as shown in Fig. 5. For the system benzene-sodium-ammonia at $20^{\circ} \mathrm{C}$, the value of $w / k T$ was estimated to 6.8 .

Another parameter $b$ at the zero concentration of 
the solute in Eq. (4) in the previous paper may be evaluated graphically or from values of more than three ternary data by the equation derived from Eq.(14) in the previous papert).

$b_{0}=$

$\frac{b_{j}\left(b_{i}-b_{k}\right)\left(M_{i}-M_{j}\right)\left(M_{k}-M_{0}\right)-b_{k}\left(b_{i}-b_{j}\right)\left(M_{i}-M_{k}\right)\left(M_{j}-M_{0}\right)}{\left(b_{i}-b_{k}\right)\left(M_{i}-M_{j}\right)\left(M_{k}-M_{0}\right)-\left(b_{i}-b_{j}\right)\left(M_{i}-M_{k}\right)\left(M_{j}-M_{0}\right)}$

where $M=\bar{x}_{2} / \bar{x}_{1}$, and subscripts $i, j, k$ represent the respective ternary data, and suffix o denotes the binary value of zero concentration of the solute. For the system benzene-sodium-ammonia at $20^{\circ} \mathrm{C}$, the value of $b$ was estimated as 48 . Estimated values in the three condensed phase region are given in Table 3 . It seems that these values would be probable, and the method described above will be useful for the estimation of solubilities in the case of sparingly soluble mixtures.

\section{Acknowledgement}

The authors would like to thank the Chiyoda Chemical Engeneering \& Construction Co., Ltd., for financial support of these experimental investigations.

\section{Nomenclature}

$b=$ constant

$d_{20}=$ specific gravity at $20^{\circ} \mathrm{C}$

$k=$ Boltzmann constant

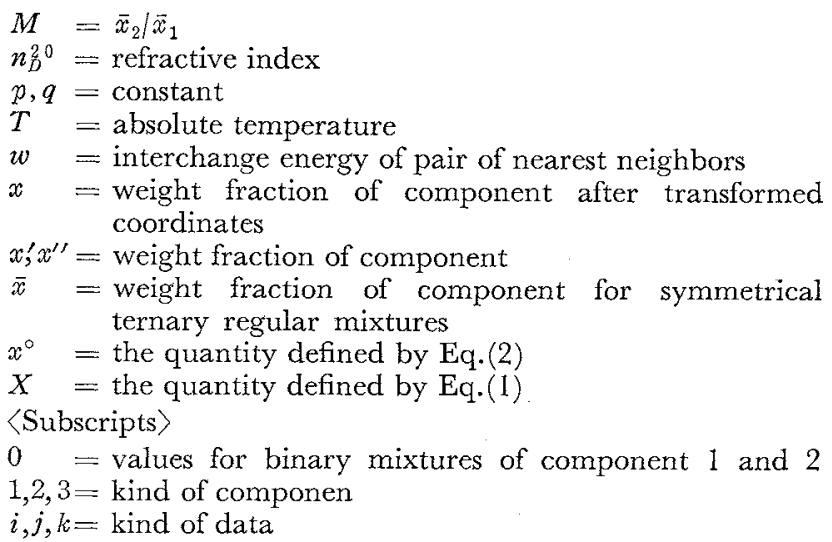

Literature cited

1) Amagasa, M.: Preprint for Petrochemical Soc. Meeting (1963)

2) Hand, D. B.: J. Phy. Chem., 34, 1961 (1930)

3) Ishida, K.: Bull. Chem. Soc. Japan, 33, 693 (1960)

4) Ishida, K.: J. Chem. Eng. Data, 6, 489 (1961)

5) Ishii, K., S. Hayami, T. Shirai and K. Ishida: $J$. Chem. Eng. Data., 11, 288 (1966)

6) Kraus, C. A.: J. Chem. Educ., 30, 83 (1953)

7) Othmer, D. F. and P. E. Tobias: Ind. Eng. Chem., 39, 693 (1942)

8) Treybal, R. E., L. D. Weber and J. F. Daley: Ind. Eng. Chem., 38, 817 (1946)

9) Waddington, T. C.: "Non-Aqueous Solvent Systems", Academic Press (1965)

\title{
DISSOCIATION PRESSURE OF SO $_{2}$-QUINOLCLATHRATE AND A METHOD FOR ITS DETERMINATION*
}

\author{
YOSHIO YOKOYAMA AND GIHEE KONNO \\ Department of Chemical Engineering, Yamagata University, \\ Yonezawa, Japan
}

\begin{abstract}
A method of general applicability and reasonable accuracy for the determination of the dissociation pressure of quinolclathrate is proposed.

The atfainment of equilibrium is remarkably accelerated by gas circulation and by the addition of liquid to the gas-solid system.

The dissociation pressures of sulfur dioxide-quinolclathrafe were determined in a temperature range of $0^{\circ} \mathrm{C}$ to $60^{\circ} \mathrm{C}$, and $\Delta H_{298}^{\circ}, \Delta G_{298}^{\circ}$ and $\Delta S_{298}^{\circ}$ were calculated.
\end{abstract}

\section{Introduction}

Petroleum refining capacity in Japan approached the 3,500,000 barrels-per-day level in 1970, while that in 1965 was $1,440,000$ barrels. At the same

* Received on February 20, 1970

Presented at the 32nd Annual Meeting of the Society of Chemical Engineers, Japan, April 1967 time, air pollution caused by sulfur dioxide has already become a social problem. To solve this, many attempts have been made, and the authors' object is the removal and recovery of hydrogen sulfide and sulfur dioxide which are the byproducts of petroleum refineries and other chemical industries.

It was found by preliminary experiment that hydrogen sulfide and sulfur dioxide were crystallized as quinolclathrate from aqueous solution of hydroquinone (often called quinol). These crystals may be de- 